Psychometric Validation of the Cross-culturally Adapted Traditional Chinese Version of the Back Beliefs Questionnaire (BBQ) and Fear Avoidance Beliefs Questionnaire (FABQ)

1

\title{
2 Abstract
}

3 Purpose: To translate and cross-culturally adapt the Back Beliefs Questionnaire (BBQ) and

4 Fear Avoidance Beliefs Questionnaire (FABQ) into traditional Chinese for their use in

5 patients experiencing low back pain (LBP)

6 Methods: This was a prospective questionnaire translation and psychometric validation of

7 the BBQ and FABQ. Double forward and single back translation of the BBQ and FABQ was

8 performed with cross-cultural adaptation. The translated questionnaires were reviewed by a

9 panel of healthcare professionals. The final version of the translated, traditional Chinese BBQ

10 and FABQ were then administered to Chinese patients with a history of back pain. Upon

11 completion, the patients also filled in the Traditional Chinese (Hong Kong) versions of the

12 Oswestry Disability Index (ODI), the Short Form 12 version 2 (SF-12v2) questionnaires and

13 visual analogue scale (VAS) for LBP. Construct validity was assessed using Spearman's

14 correlation test against the subscales and domains with similar constructs. Internal 
1 determined by known group comparisons.

2 Results: A total of 100 patients were recruited. Both BBQ and FABQ demonstrated an

3 excellent overall internal consistency ( $\alpha=0.810$ and 0.859 respectively). The BBQ scores

4 significantly correlated with ODI scores, VAS-LBP and all domains of SF-12v2

$5 \quad(\mathrm{p}<0.01-0.05)$; whereas only FABQ Work subscale correlated with ODI scores $(\mathrm{p}<0.01)$ and

6 VAS-LBP $(\mathrm{p}<0.05)$. Both FABQ subscales correlated with only specific domains of SF-12v2

$7 \quad(\mathrm{p}<0.01-0.05)$. The translated BBQ was sensitive to patients with or without a history of

8 trauma relating to spine/accidental fall. The FABQ-W was sensitive to difference between

9 patients with acute versus chronic back pain, and in patients with or without a history of spinal

10 tumour or infection.

11 Conclusions: Both the adapted BBQ and FABQ (Traditional Chinese-Hong Kong) were

12 demonstrated to have satisfactory psychometric properties, with adequate internal

13 consistencies, construct validity and sensitivity to the certain clinical parameters. These

14 findings verify the use of both questionnaires in Chinese patients with LBP, and provide

15 instruments for future investigations regarding back pain, their management and treatment

16 outcomes.

18 Keywords: Psychometrics; low back pain; BBQ; FABQ

19 Level of evidence: 2 


\section{Introduction}

3

4

5 from various aetiological factors, be it pathological in nature and/or a consequence of

6 physical factors such as injury or exertion, or mental strain. However, LBP can be beyond

7 just a medical entity from patient's perspective, as the pain can lead to absence from work

8 and negatively impacts health-related quality of life (HRQOL).[2] Such low back disability

9 conjures up the low back trouble, which as defined by Symonds et al[3] consists of two separate components, the clinical syndrome and the disability that is predominantly controlled by psychosocial factors.[4]

12 Therefore, in order to gain comprehensive understanding of low back pain and its impact, psychosocial factors like the beliefs and attitudes of patients towards their own experience of

14 LBP are important, in addition to pain aetiology and severity. Patient-orientated instruments specifically focusing on back pain beliefs are thus required for investigating various beliefs about pain and disability. The Back Beliefs Questionnaire (BBQ) was developed to measure an

17 individual's beliefs towards various inevitable consequences of the future as a result of low

18 back trouble.[3, 5] It has been translated and cross-culturally adapted in Saudi Arabia and Iran, 
1 professionals.[8] Another self-rated belief instrument is the Fear Avoidance Beliefs

2 Questionnaire (FABQ). Fear avoidance beliefs, in fact, are psychological risk factors for LBP

3 to persist and develop into a chronic nature.[9] This is based on the fear-avoidance model,

4 which explains how acute/subacute pain patients might be transitioned into a chronic state of

5 depression, disability, and inactivity over time.[10] The FABQ were culturally adapted in a

6 large number of countries,[11-20] for the purpose of not only its use in local population, but

7 more importantly to seek its validity in the assessment of treatment efficacy and outcome.[21]

8 As these beliefs questionnaires are structured to gain psychosocial data using a list of back

9 pain-related statements, it is of particular importance to adapt such tool into colloquial local

10 language in order to effectively capture patients' perception of the back pain trouble. Hence the

11 aim of this study is to translate and culturally-adapting the BBQ and FABQ into traditional

12 Chinese, and to validate its use in the patients of Chinese ethnicity with LBP.

14 Materials and Methods

15 Subjects and Setting

16 Consecutive Chinese patients attending a specialty back pain outpatient clinic during the

17 period of April 2016 and November 2016 were recruited. Exclusion criteria included illiterate

18 patients, or those who could not communicate either verbally in Cantonese and/or understand

19 traditional Chinese characters in writing. A sample size of 100 was planned for recruitment, 
1 as sample sizes of 50 to 100 is considered good to excellent as according to the COSMIN

2 checklist, an international consensus quality assessment of psychometric evaluation.[22]

3 Ethics approval was obtained from the institutional review board.

4 Subjects who consented were invited to fill in the translated BBQ (Traditional Chinese -

5 Hong Kong) and FABQ (Traditional Chinese - Hong Kong). Upon completion, the patients

6 were also asked to complete the Traditional Chinese (Hong Kong) version of the Oswestry

7 Disability Index (ODI) and the Short term 12-item Health Survey version 2 (SF-12v2)

8 questionnaires. A visual analogue scale (VAS) was used to ask patients to rate the degree of

9 their LBP on the day.

10 At the time of visit, demographic and clinical data were collected. Episodes of LBP was

11 reported as acute ( $<6$ weeks duration) or chronic ( $\geq 12$ weeks duration),[23] as well as only

12 back pain or with radiating leg pain and numbness. Diagnoses included spinal deformities

13 (scoliosis, spondylolisthesis), disc degeneration, and lumbar spondylosis (degeneration with

14 osteophytes). Histories of any previous spine surgery, any previous trauma relating to spine or

15 accidental fall were also extracted.

17 Translation and Cross-culture Adaptation

18 By following one of the internationally accepted translation techniques,[24] the original

19 English version of BBQ and FABQ were translated into traditional Chinese (Hong Kong). 
1 This consisted of double forward translation and single back translation by independent

2 professional translators, who are native speakers of Cantonese, and can communicate using

3 local terms in the written form of traditional Chinese used in Hong Kong. After the first

4 forward translation, the translated traditional Chinese version of BBQ and FABQ was

5 reviewed by a panel of local healthcare professionals (inclusive of spine specialists and allied

6 health professionals). It was then back-translated into English by a professional translator

7 who had no prior knowledge of the original questionnaire. The final forward translation was

8 performed by an independent translator. The final version of the translated and

9 culturally-adapted BBQ and FABQ in traditional Chinese (Hong Kong) was finalized and 10 approved by the review panel. (Appendix 1)

12 Study Instruments

13 Back Beliefs Questionnaire (BBQ)

14 BBQ was developed to focus on various inevitable aspects of LBP. It is comprised of 15 one scale using a sub-set of 9 statements, together with another 5 statements being the 16 distractors.[3] A 5-point Likert scale was used for each statement, ranging from 1 (strongly

17 disagree) to 5 (strongly agree). The scale is then calculated by reversing and summation of

18 the 9 scores, with a possible score ranged between 9 to 45. More pessimistic beliefs about back pain are indicated by lower scores. 
2 Fear Avoidance Beliefs Questionnaire (FABQ)

3 This questionnaire was developed based on theories of fear and avoidance behaviour.

4 The FABQ quantifies patients' fear of pain and consequent avoidance of physical activity

5 because of their fear.[4, 25] It consists of a total of 16 items, of which each item scored from

60 to 6. There are two subscales: the Work Subscales (FABQ-W) and the Physical Activity

7 Subscale (FABQ-PA), with seven and four items respectively and 5 remaining items as

8 ineffective. These two subscales allow the identification of patient's beliefs on how work and

9 physical activity affect their current LBP, and they were demonstrated to be reliable and valid

10 for the measurement of fear-avoidance beliefs.[4] Greater fear and avoidance beliefs are

11 represented by the higher scores of the FABQ.

12 In addition, there was a five-point Likert scale immediately upon completion of the

13 translated BBQ and FABQ, with 5 levels of responses: Strongly Agree, Agree, Neither

14 agree/disagree, Disagree, Strongly Disagree. This allowed patients to rate the clarity and 15 understanding of translated questionnaires.

17 Oswestry Disability Index (ODI) Questionnaire

The Oswestry Low Back Pain Disability Questionnaire is an outcome measure designed to assess limitations of various activities of daily living, by which the ODI is derived. The 
1 questionnaire consists of ten sections, of which each is scored on a $0-5$ scale, with increasing

2 level of disability. The index is calculated by dividing the summed score by the total possible

3 score and expressed as a percentage. It is considered the 'gold standard' of low back

4 functional outcome tools, and is used to measure patient's permanent functional disability.[26,

5 27] The use of ODI in the Hong Kong Chinese population has been validated.[28]

6

7 Short Form 12 - version $2(\mathrm{SF}-12 \mathrm{v} 2)$

8 The SF-12v2 Health Survey is a shorter version of the SF-36v2 Health Survey. It is a

9 generic, HRQOL measure that assesses the functional health and well-being from patients'

10 own perception. It consists of twelve questions, designated into eight domains from which the

11 two composite scores of mental and physical health are derived. SF-12v2 was found to be a

12 valid, sensitive and reliable substitute of the SF-36v2 for the Chinese in Hong Kong.[29]

14 Statistical Analysis

15 Descriptive statistics of the study population, including mean, standard deviation (SD)

16 and percentage, were calculated. The construct validity of the BBQ and FABQ domains was

17 assessed using Spearman's correlation test against the domain scores of SF-12v2 with similar

18 constructs. The internal consistency reliability was assessed by Cronbach's alpha ( $\alpha$ ), whose

19 value $>0.7$ represents adequate internal consistency. If the $\alpha$ for an instrument is below 0.6 , 
1 then its reliability may be questioned.[30] The sensitivity of the translated BBQ and FABQ

2 was determined by known group comparisons using independent t-test and analysis of

3 variance, where appropriate. Comparisons of known clinical groups were among patients

4 who had a history of previous spine surgery, a history of trauma relating to the spine or

5 accidental fall, diagnosis of spinal deformities (scoliosis, spondylolisthesis), disc

6 degeneration, lumbar spondylosis/ degeneration with osteophytes, as well as examining

7 patients with acute or chronic or acute on chronic LBP, and location of pain (back only versus

8 back and leg pain with or without numbness).

9 Data analyses were conducted using SPSS Windows 23.0 (IBM SPSS Inc., Chicago, IL, 10 USA) and STATA version 13.0 (StataCorp LP. College Station, Texas, U.S.). P-value <0.05

11 was statistically significant.

14 Results

16 a total of 100 patients (57\% females) were recruited with mean age of $57.0 \pm 12.5$ years. Table

171 presents the demographics and clinical characteristics of patients. The descriptive statistics

18 of BBQ and FABQ, ODI and SF-12v2 subscale and summary score are detailed in Table 2.

19 For the translated BBQ, 82\% of patients agreed or strongly agreed that the translated 
1 questionnaire was clear and understandable, and none disagreed. (Appendix 2) For the

2 translated FABQ, 73\% of patients agreed or strongly agreed that the questionnaire was clear

3 and understandable with 2\% who disagreed. (Appendix 3)

$4 \quad$ Psychometric testing revealed that both BBQ and FABQ demonstrated an excellent

5 overall internal consistency with $\alpha=0.810$ and 0.859 respectively. (Table 3) For the FABQ

6 with the two subscales, FABQ-W had a good internal consistency of 0.875 as compared to

7 that of FABQ-PA $(\alpha=0.606)$. In addition, BBQ correlated significantly with both FABQ

8 subscales $(\mathrm{p}<0.01)$. The BBQ scores significantly correlated with ODI scores as well as all

9 domains of SF-12v2 $(\mathrm{p}<0.01-0.05)$ whereas only FABQ-W correlated with ODI scores

10 ( $<<0.01)$. FABQ-PA correlated significantly $(\mathrm{p}<0.01-0.05)$ with the domains of Bodily Pain,

11 Social Functioning, Role Emotional, Mental Health and the Mental Composite Summary

12 score of SF12v2, and the FABQ-W had significant correlations to domains of Physical

13 Functioning, Role Physical, Bodily Pain, Social Functioning, Role Emotional, and the

14 Physical Composite Summary score. Moreover, LBP VAS score significantly correlated

$15(\mathrm{p}<0.01-0.05)$ with BBQ score and FABQ-W. Both translated belief instruments, BBQ and

16 the two subscales of FABQ correlated with each other $(\mathrm{p}<0.01)$.

17 For known-group validity, the translated questionnaires were tested for their sensitivity

18 as per results in Table 4. BBQ was sensitive to patients with or without a history of trauma

19 relating to spine/accidental fall. For FABQ, the FABQ-W subscale was sensitive to differences 
1 between patients with acute versus chronic back pain, as well as in patients with or without a

2 history of spinal tumour or infection. The FABQ-PA was not sensitive to any known groups.

3

4 Discussion

5

Psychosocial factors, which involve fear-avoidance beliefs and beliefs of back problem,

6 are important risk factors of chronic LBP, which can interfere with work and HRQOL.[31]

7 The role of psychosocial factors in the interplay between back pain, disability and physical

8 activity should not be underestimated, particularly in terms of recovery and treatment

9 outcomes. Fear avoidance beliefs can be modified to possibly improve treatment outcome,[21]

10 and are associated with self-rated disability and work loss.[4, 32] It is thus desirable to

11 establish reliable measures for assessing patients' beliefs towards LBP, in the aid of eliciting

12 psychosocial data which can contribute to a more effective management of LBP and its

13 related disability.

14 Both translated BBQ and FABQ demonstrated an excellent overall internal consistency,

15 with a better internal consistency for the Work subscale than the Physical Activity subscale

16 for FABQ. This is similar to the results of the original version, as well as those found in other

17 validation studies of the translated FABQ.[3, 4, 13] The BBQ scores had significant though

18 weak correlations with all domains of SF12v2 whereas both subscales of FABQ also had such 
1 SF12v2. These suggest that both translated questionnaires contain pain and psychosocial

2 components (in terms of emotion and social function as tested in the domains of the generic

3 SF12v2). The fact that each of FABQ-PA and FABQ-W correlated to other various domains of

4 SF12v2 suggested that each subscale is complementary of each other. In addition, correlation

5 existed between BBQ and VAS-LBP score, indicating that the more severe the LBP, the more

6 pessimistic the patients perceive about back pain. The negative, significant correlation of

7 FABQ-W and VAS-LBP score suggests that the more severe the LBP patients experience, the

8 greater their fear-avoidance beliefs.

Also, the translated BBQ and FABQ-W were found to be correlated with the LBP disability questionnaire ODI, demonstrating that the data captured by the translated

11 questionnaires have a significant relationship with the ODI responses. This can be explained

12 by the existing evidence that fear avoidance beliefs strongly influence the patient's perception

13 of pain-related disability.[33] The correlation recognizes the relationship between disability

14 and patient's back pain beliefs/beliefs of work activity being a cause of their LBP, and on their

15 fear of perceived danger of work activity when they have an episode of LBP. Previous findings

16 actually reveal individuals with long work absence due to LBP had more negative beliefs about

17 work activities in relation to their back pain.[34]

The sensitivity of the translated FABQ, whose subscale FABQ-W, ascertains its ability in demonstrating significant difference between patients who experience acute versus chronic 
1 pain, and those patients with/without spinal infection or tumour. In adjunct, BBQ is sensitive

2 in differentiating among patients with or without a history of trauma to the spine/accidental

3 fall. Those with such history had significantly lower BBQ scores and had more pessimistic

4 beliefs about back pain. Importantly, negative pain beliefs can contribute to the transition

5 from acute pain to persistent pain.[35] These negative beliefs can develop into fear-avoidance

6 beliefs, including the fear of pain, injury or re-injury. These fear-avoidance beliefs can then

7 result in a reduced level of physical activities and an increased level of disability.[36]

8 Therefore such sensitivities of the instruments are desirable as the questionnaires have taken

9 into account patients' previous back-related histories when assessing their current beliefs of

10 back pain condition, These parameters could have already contributed significant differences

11 in belief scores at baseline.

The translated back pain-specific instruments not only facilitate the collection of

13 psychosocial data of LBP patients, they allow the identification of acute pain patients who are

14 at risk of having pain persisting to a chronic nature, and can provide indications of those at risk

15 of prolonged or delayed recovery. Previous studies found that fear-avoidance beliefs are

16 associated with poor treatment outcome in patients with LBP of less than 6 months.[21] Thus

17 for acute pain patients with high fear avoidance beliefs, the treatment approach can be

18 multifaceted to incorporate psychological aspects, educational or fear-exposure measures. The

19 timely administration of the multidisciplinary approach in the early stages of LBP can prevent 
1 chronicity of pain and disability.[9] This is especially applicable to primary care settings.[37]

2 This is rather crucial as for acute/subacute LBP patients, there is no clinically meaningful

3 relationship between physical activity and disability.[38] On the contrary, high fear avoidance

4 beliefs were found to be associated with more pain and or disability and less return to work;

5 whereas reduction of pain-related fear concurred with decreased disability and elevated

6 physical activities.[39] Therefore the indication of the level of fear avoidance beliefs and

7 negative pain beliefs is also important in patients with recurrent episodes of LBP, or of chronic

8 nature. Fear-avoidance beliefs appear to have predictive power in analyses of disability and

$9 \quad$ work loss.[32]

The main limitation of this study is that the subject recruitment was at a single outpatient

11 specialty clinic, as compared to a multi-center study. The data is also only representative of a

12 single time-point, further study is required to examine the responsiveness of the translated

13 questionnaires, such as testing the psychometric properties before and after interventions. The

14 longitudinal comparison of patients' beliefs on back pain can then hopefully improve not only

15 treatment outcome, but the efficacy and cost-effectiveness of clinical intervention. Also, it is

16 important to emphasize that the sensitivity of score changes of BBQ and FABQ, especially to

17 patients with a history of trauma or infection / tumour, should be interpreted with caution.

18 The study has limited statistical power for comparing patients with history of trauma or 
1

\section{References}

14 1. Vos T, Flaxman AD, Naghavi M, Lozano R, Michaud C, Ezzati M, Shibuya K, Salomon JA, the general population. Future study to reexamine these subgroups may be required.

\section{Conclusion}

The translated BBQ and FABQ (Traditional Chinese-Hong Kong) demonstrated satisfactory psychometric properties, with adequate internal consistencies, construct validity and sensitivities to the certain clinical parameters. This validation allows these measures to be used as a common tool for healthcare professionals to screen for patients who are at risk of developing chronic LBP from an acute condition, and those who may experience slower recovery rate, or prolonged rehabilitation. Further exploration of the translated BBQ and FABQ in relation to clinical interventions is required.

infection / tumour due to the relative small sample size in a specialist outpatient clinic and in

15 Abdalla S, Aboyans V, Abraham J, Ackerman I, Aggarwal R, Ahn SY, Ali MK, Alvarado M,

16 Anderson HR, Anderson LM, Andrews KG, Atkinson C, Baddour LM, Bahalim AN,

17 Barker-Collo S, Barrero LH, Bartels DH, Basanez MG, Baxter A, Bell ML, Benjamin EJ,

18 Bennett D, Bernabe E, Bhalla K, Bhandari B, Bikbov B, Bin Abdulhak A, Birbeck G, Black

19 JA, Blencowe H, Blore JD, Blyth F, Bolliger I, Bonaventure A, Boufous S, Bourne R, 
1 Boussinesq M, Braithwaite T, Brayne C, Bridgett L, Brooker S, Brooks P, Brugha TS,

2 Bryan-Hancock C, Bucello C, Buchbinder R, Buckle G, Budke CM, Burch M, Burney P,

3 Burstein R, Calabria B, Campbell B, Canter CE, Carabin H, Carapetis J, Carmona L, Cella C,

4 Charlson F, Chen H, Cheng AT, Chou D, Chugh SS, Coffeng LE, Colan SD, Colquhoun S,

5 Colson KE, Condon J, Connor MD, Cooper LT, Corriere M, Cortinovis M, de Vaccaro KC,

6 Couser W, Cowie BC, Criqui MH, Cross M, Dabhadkar KC, Dahiya M, Dahodwala N,

7 Damsere-Derry J, Danaei G, Davis A, De Leo D, Degenhardt L, Dellavalle R, Delossantos A,

8 Denenberg J, Derrett S, Des Jarlais DC, Dharmaratne SD, Dherani M, Diaz-Torne C, Dolk H,

9 Dorsey ER, Driscoll T, Duber H, Ebel B, Edmond K, Elbaz A, Ali SE, Erskine H, Erwin PJ,

10 Espindola P, Ewoigbokhan SE, Farzadfar F, Feigin V, Felson DT, Ferrari A, Ferri CP, Fevre

11 EM, Finucane MM, Flaxman S, Flood L, Foreman K, Forouzanfar MH, Fowkes FG, Franklin

12 R, Fransen M, Freeman MK, Gabbe BJ, Gabriel SE, Gakidou E, Ganatra HA, Garcia B,

13 Gaspari F, Gillum RF, Gmel G, Gosselin R, Grainger R, Groeger J, Guillemin F, Gunnell D,

14 Gupta R, Haagsma J, Hagan H, Halasa YA, Hall W, Haring D, Haro JM, Harrison JE,

15 Havmoeller R, Hay RJ, Higashi H, Hill C, Hoen B, Hoffman H, Hotez PJ, Hoy D, Huang JJ,

16 Ibeanusi SE, Jacobsen KH, James SL, Jarvis D, Jasrasaria R, Jayaraman S, Johns N, Jonas JB,

17 Karthikeyan G, Kassebaum N, Kawakami N, Keren A, Khoo JP, King CH, Knowlton LM,

18 Kobusingye O, Koranteng A, Krishnamurthi R, Lalloo R, Laslett LL, Lathlean T, Leasher JL, 
1 SL, Lyons R, Ma J, Mabweijano J, MacIntyre MF, Malekzadeh R, Mallinger L, Manivannan

2 S, Marcenes W, March L, Margolis DJ, Marks GB, Marks R, Matsumori A, Matzopoulos R,

3 Mayosi BM, McAnulty JH, McDermott MM, McGill N, McGrath J, Medina-Mora ME,

4 Meltzer M, Mensah GA, Merriman TR, Meyer AC, Miglioli V, Miller M, Miller TR, Mitchell

5 PB, Mocumbi AO, Moffitt TE, Mokdad AA, Monasta L, Montico M, Moradi-Lakeh M,

6 Moran A, Morawska L, Mori R, Murdoch ME, Mwaniki MK, Naidoo K, Nair MN, Naldi L,

7 Narayan KM, Nelson PK, Nelson RG, Nevitt MC, Newton CR, Nolte S, Norman P, Norman

8 R, O'Donnell M, O'Hanlon S, Olives C, Omer SB, Ortblad K, Osborne R, Ozgediz D, Page A,

9 Pahari B, Pandian JD, Rivero AP, Patten SB, Pearce N, Padilla RP, Perez-Ruiz F, Perico N,

10 Pesudovs K, Phillips D, Phillips MR, Pierce K, Pion S, Polanczyk GV, Polinder S, Pope CA,

11 3rd, Popova S, Porrini E, Pourmalek F, Prince M, Pullan RL, Ramaiah KD, Ranganathan D,

12 Razavi H, Regan M, Rehm JT, Rein DB, Remuzzi G, Richardson K, Rivara FP, Roberts T,

13 Robinson C, De Leon FR, Ronfani L, Room R, Rosenfeld LC, Rushton L, Sacco RL, Saha S,

14 Sampson U, Sanchez-Riera L, Sanman E, Schwebel DC, Scott JG, Segui-Gomez M, Shahraz

15 S, Shepard DS, Shin H, Shivakoti R, Singh D, Singh GM, Singh JA, Singleton J, Sleet DA,

16 Sliwa K, Smith E, Smith JL, Stapelberg NJ, Steer A, Steiner T, Stolk WA, Stovner LJ,

17 Sudfeld C, Syed S, Tamburlini G, Tavakkoli M, Taylor HR, Taylor JA, Taylor WJ, Thomas B,

18 Thomson WM, Thurston GD, Tleyjeh IM, Tonelli M, Towbin JA, Truelsen T, Tsilimbaris MK,

19 Ubeda C, Undurraga EA, van der Werf MJ, van Os J, Vavilala MS, Venketasubramanian N, 
1 Wang M, Wang W, Watt K, Weatherall DJ, Weinstock MA, Weintraub R, Weisskopf MG,

2 Weissman MM, White RA, Whiteford H, Wiersma ST, Wilkinson JD, Williams HC, Williams

3 SR, Witt E, Wolfe F, Woolf AD, Wulf S, Yeh PH, Zaidi AK, Zheng ZJ, Zonies D, Lopez AD,

4 Murray CJ, AlMazroa MA, Memish ZA (2012) Years lived with disability (YLDs) for 1160

5 sequelae of 289 diseases and injuries 1990-2010: a systematic analysis for the Global Burden

6 of Disease Study 2010. Lancet (London, England) 380:2163-2196. doi:

7 10.1016/s0140-6736(12)61729-2

8 2. Montazeri A, Mousavi SJ (2010) Quality of Life and Low Back Pain. In: Preedy VR,

9 Watson RR (eds) Handbook of Disease Burdens and Quality of Life Measures. Springer New

10 York, New York, NY. pp. 3979-3994.

11 3. Symonds TL, Burton AK, Tillotson KM, Main CJ (1996) Do attitudes and beliefs influence

12 work loss due to low back trouble? Occupational medicine (Oxford, England) 46:25-32

13 4. Waddell G, Newton M, Henderson I, Somerville D, Main CJ (1993) A Fear-Avoidance

14 Beliefs Questionnaire (FABQ) and the role of fear-avoidance beliefs in chronic low back pain

15 and disability. Pain 52:157-168

16 5. Symonds TL, Burton AK, Tillotson KM, Main CJ (1995) Absence resulting from low back

17 trouble can be reduced by psychosocial intervention at the work place. Spine 20:2738-2745

18 6. Alamrani S, Alsobayel H, Alnahdi AH, Moloney N, Mackey M (2016) Cross-Cultural

19 Adaptation and Validation of the Back Beliefs Questionnaire to the Arabic Language. Spine 
1

2 7. Rostami M, Noorian N, Mansournia MA, Sharafi E, Babaki AE, Kordi R (2014) Validation

3 of the Persian version of the fear avoidance belief questionnaire in patients with low back

4 pain. Journal of back and musculoskeletal rehabilitation 27:213-221. doi:

$5 \quad 10.3233 / \mathrm{bmr}-130439$

6 8. Chen G, Tan BK, Jia HL, O'Sullivan P, Burnett A (2011) Questionnaires to examine Back

7 Pain Beliefs held by health care professionals: a psychometric evaluation of Simplified

8 Chinese versions. Spine (Phila Pa 1976) 36:1505-1511. doi: 10.1097/BRS.0b013e3181f49eec

9 9. Hasenbring M, Hallner D, Klasen B (2001) [Psychological mechanisms in the transition 10 from acute to chronic pain: over- or underrated?]. Schmerz (Berlin, Germany) 15:442-447.

11 doi: $10.1007 / \mathrm{s} 004820100030$

12 10. Vlaeyen JW, Linton SJ (2000) Fear-avoidance and its consequences in chronic 13 musculoskeletal pain: a state of the art. Pain 85:317-332

14 11. Simoncsics E, Stauder A (2017) [Fear and avoidance beliefs in chronic pain. The 15 translation and validation of the Hungarian version of the FABQ questionnaire]. Orvosi 16 hetilap 158:949-955. doi: 10.1556/650.2017.30764

17 12. Alanazi F, Gleeson P, Olson S, Roddey T (2017) Translation and Validation of the Arabic

18 Version of the Fear-Avoidance Beliefs Questionnaire in Patients With Low Back Pain. Spine 19 
1 13. Terho H, Haapea M, Paananen M, Korniloff K, Hakkinen A, Karppinen J (2016)

2 Translation and validation of the Finnish version of the Fear-Avoidance Beliefs Questionnaire

3 (FABQ). Scandinavian journal of pain 10:113-118. doi: 10.1016/j.sjpain.2015.09.003

4 14. Pfingsten M, Kroner-Herwig B, Leibing E, Kronshage U, Hildebrandt J (2000) Validation

5 of the German version of the Fear-Avoidance Beliefs Questionnaire (FABQ). European

6 journal of pain (London, England) 4:259-266. doi: 10.1053/eujp.2000.0178

7 15. Korkmaz N, Akinci A, Yorukan S, Surucu HS, Saracbasi O, Ozcakar L (2009) Validation

8 and reliability of the Turkish version of the fear avoidance beliefs questionnaire in patients

9 with low back pain. European journal of physical and rehabilitation medicine 45:527-535

10 16. Grotle M, Brox JI, Vollestad NK (2006) Reliability, validity and responsiveness of the

11 fear-avoidance beliefs questionnaire: methodological aspects of the Norwegian version.

12 Journal of rehabilitation medicine 38:346-353. doi: 10.1080/16501970600722403

13 17. Monticone M, Baiardi P, Bonetti F, Ferrari S, Foti C, Pillastrini P, Rocca B, Vanti C,

14 Zanoli G (2012) The Italian version of the Fear-Avoidance Beliefs Questionnaire (FABQ-I):

15 cross-cultural adaptation, factor analysis, reliability, validity, and sensitivity to change. Spine

16 37:E374-380. doi: 10.1097/BRS.0b013e31822ff5a7

17 18. Matsudaira K, Kikuchi N, Murakami A, Isomura T (2014) Psychometric properties of the 18 Japanese version of the Fear-Avoidance Beliefs Questionnaire (FABQ). Journal of orthopaedic science : official journal of the Japanese Orthopaedic Association 19:26-32. doi: 
1

2

3

4

5

6

7 rehabilitation 9:532-535. doi: 10.12965/jer.130079

8 21. Wertli MM, Rasmussen-Barr E, Held U, Weiser S, Bachmann LM, Brunner F (2014)

9 Fear-avoidance beliefs-a moderator of treatment efficacy in patients with low back pain: a

10.1007/s00776-013-0471-5

19. Pei LB, Xia JJ, Yan JL (2010) Cross-cultural adaptation, reliability and validity of the

Chinese version of the Fear Avoidance Beliefs Questionnaire. J Int Med Res 38:1985-1996.

doi: $10.1177 / 147323001003800612$

20. Chung EJ, Hur YG, Lee BH (2013) A study of the relationship among fear-avoidance beliefs, pain and disability index in patients with low back pain. Journal of exercise systematic review. The spine journal : official journal of the North American Spine Society 14:2658-2678. doi: 10.1016/j.spinee.2014.02.033

22. Terwee CB, Mokkink LB, Knol DL, Ostelo RW, Bouter LM, de Vet HC (2012) Rating the methodological quality in systematic reviews of studies on measurement properties: a scoring system for the COSMIN checklist. Quality of life research : an international journal of quality of life aspects of treatment, care and rehabilitation 21:651-657. doi: 10.1007/s11136-011-9960-1

23. van Tulder M, Becker A, Bekkering T, Breen A, del Real MT, Hutchinson A, Koes B, Laerum E, Malmivaara A (2006) Chapter 3. European guidelines for the management of acute nonspecific low back pain in primary care. Eur Spine J 15 Suppl 2:S169-191. doi: 
1

2

3

4

5

6

7 work-related low back pain: the importance of fear-avoidance beliefs. Physical therapy

$8 \quad 82: 973-983$

9

10 discussion 2952

11

17 valid and equivalent substitute for the SF-36 version 2 Health Survey for the Chinese?

18 Journal of evaluation in clinical practice 19:200-208. doi: 10.1111/j.1365-2753.2011.01800.x

\subsection{7/s00586-006-1071-2}

24. Acquadro C, Conway K, Hareendran A, Aaronson N (2008) Literature review of methods to translate health-related quality of life questionnaires for use in multinational clinical trials.

Value in health : the journal of the International Society for Pharmacoeconomics and Outcomes Research 11:509-521. doi: 10.1111/j.1524-4733.2007.00292.x

25. Fritz JM, George SZ (2002) Identifying psychosocial variables in patients with acute 26. Fairbank JC, Pynsent PB (2000) The Oswestry Disability Index. Spine 25:2940-2952; 27. Mehra A, Baker D, Disney S, Pynsent PB (2008) Oswestry Disability Index scoring made easy. Annals of the Royal College of Surgeons of England 90:497-499. doi:

\section{$10.1308 / 003588408 \times 300984$}

28. Chow JH, Chan CC (2005) Validation of the Chinese version of the Oswestry Disability Index. Work (Reading, Mass) 25:307-314

29. Lam ET, Lam CL, Fong DY, Huang WW (2013) Is the SF-12 version 2 Health Survey a Journal of evaluation in chinical practice 19:200-208. doi: 10.1111/j.1365-2753.2011.01800.x 30. McKennell A (1970) Atititude Measurement: Use of Coefficient Alpha with Cluster or 
1

2

3

4

5

6

7

8

9

10

11

12

13

14

15

16

17 Psychosocial risk factors for chronic low back pain in primary care--a systematic review.

18 Family practice 28:12-21. doi: 10.1093/fampra/cmq072

19

Factor Analysis. Sociology 4:227-245

31. Yoshimoto T, Oka H, Katsuhira J, Fujii T, Masuda K, Tanaka S, Matsudaira K (2017)

Prognostic psychosocial factors for disabling low back pain in Japanese hospital workers.

PloS one 12:e0177908. doi: 10.1371/journal.pone.0177908

32. Staerkle R, Mannion AF, Elfering A, Junge A, Semmer NK, Jacobshagen N, Grob D,

Dvorak J, Boos N (2004) Longitudinal validation of the fear-avoidance beliefs questionnaire

(FABQ) in a Swiss-German sample of low back pain patients. European spine journal :

official publication of the European Spine Society, the European Spinal Deformity Society, and the European Section of the Cervical Spine Research Society 13:332-340. doi: $10.1007 / \mathrm{s} 00586-003-0663-3$

33. Mannion AF, Junge A, Taimela S, Muntener M, Lorenzo K, Dvorak J (2001) Active therapy for chronic low back pain: part 3. Factors influencing self-rated disability and its change following therapy. Spine 26:920-929

34. Lehmann TR, Spratt KF, Lehmann KK (1993) Predicting long-term disability in low back injured workers presenting to a spine consultant. Spine 18:1103-1112

35. Ramond A, Bouton C, Richard I, Roquelaure Y, Baufreton C, Legrand E, Huez JF (2011)

36. Leeuw M, Goossens ME, Linton SJ, Crombez G, Boersma K, Vlaeyen JW (2007) The 
1 fear-avoidance model of musculoskeletal pain: current state of scientific evidence. Journal of

2 behavioral medicine 30:77-94. doi: 10.1007/s10865-006-9085-0

3 37. Linton SJ, Andersson T (2000) Can chronic disability be prevented? A randomized trial of

4 a cognitive-behavior intervention and two forms of information for patients with spinal pain.

5 Spine 25:2825-2831; discussion 2824

6 38. Lin CW, McAuley JH, Macedo L, Barnett DC, Smeets RJ, Verbunt JA (2011)

7 Relationship between physical activity and disability in low back pain: a systematic review

8 and meta-analysis. Pain 152:607-613. doi: 10.1016/j.pain.2010.11.034

9 39. Vlaeyen JW, de Jong J, Geilen M, Heuts PH, van Breukelen G (2002) The treatment of 10 fear of movement/(re)injury in chronic low back pain: further evidence on the effectiveness

11 of exposure in vivo. The Clinical journal of pain 18:251-261 